\title{
短軸回りに回転するラグビーボールの空力特性*
}

\author{
瀬尾和 哉*1, 小林 修*2, 村上 正 秀*3
}

\section{Aerodynamic Characteristics of a Rugby Ball Spinning on Its Transverse Axis}

\author{
Kazuya SEO*4, Osamu KOBAYASHI and Masahide MURAKAMI \\ ${ }^{* 4}$ Faculty of Education, Art and Science, Yamagata University, \\ 1-4-12 Kojirakawa, Yamagata-shi, Yamagata, 990-8560 Japan
}

\begin{abstract}
We have measured aerodynamic forces and moments acting on a rugby ball spinning on its transverse axis by wind tunnel experiments. A full-size model of a rugby ball was tested in a lowspeed wind tunnel with a $1.5 \mathrm{~m} \times 1.0 \mathrm{~m}$ rectangular nozzle. It was made of fiber reinforced plastics by molding a fully-inflated ball. The spinning mechanism was composed of a motor and four shafts inserted the ball along its transverse axis. The results are summarized as follows: the lift increases with increasing the spin rate because of the Magnus force. The Magnus force is at its maximum when the spinning (transverse) axis is perpendicular to the flight direction. The side force depends on the angle between the spinning axis and the direction of flight. The side force is a maximum when this angle is $45^{\circ}$.
\end{abstract}

Key Words : Aerodynamic Forces, Kick for Goal, Rugby, Spinning Ball

\section{1. 緒言}

ラグビーボールの飛しょうを回転に着目し, 分類す ると三つに分けられる。長軸回りに回転するスクリュ ーキック ${ }^{(1)(2)}$ ，ほぼ無回転のハイパント(3)，短軸回りに 回転するゴールキックやドロップキックである.なか でもゴールキックは直接得点につながるキックで, 重 要である、ゴールを成功させるためには，キッカはあ る制限された初期条件の範囲でボールをけり出さなけ ればならない。この条件を知るためには，ボールに働 く空気力と飛しょう軌跡の計算が必須である。しか し, 短軸回りに回転するラグビーボールの空気力を測 定した例はほとんどない(4).

本論文では，ゴールキックを模擬した風洞実験につ いて，その結果を報告する，短軸回りに回転するラグ ビーボールには, 回転による揚力(マグヌス力) とボー ル形状に起因する横力およびヨーイングモーメントが 働くことが明らかになった。

* 原稿受付 2006 年 11 月 6 日.

*1 正員, 山形大学地域教育文化学部(亚 990-8560 山形市小白 川 1-4-12).

*2 正員, 東海大学工学部.

*3 筑波大学大学院システム情報工学研究科.

E-mail : seo@e.yamagata-u.ac.jp
記 号

$$
\begin{aligned}
& C_{D} \text { : 抗力係数 } \\
& C_{L} \text { : 揚力係数 }
\end{aligned}
$$

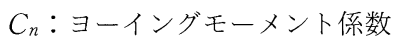

$$
\begin{aligned}
& C_{Y}: \text { 横力係数 } \\
& D \text { : 抗力 } \mathrm{N} \\
& L \text { :揚力 } \mathrm{N}
\end{aligned}
$$

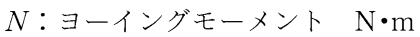

$$
\begin{aligned}
& S p: \text { スピンパラメータ }=\pi \omega V_{b}^{1 / 3} /|\vec{V}| \\
& S D ： \text { 標準偏差 } \\
& \vec{V}: \text { 速度ベクトル } \mathrm{m} / \mathrm{s} \\
& V_{b}: \text { ラグビーボール体積 } \mathrm{m}^{3} \\
& Y: \text { 横力 } \mathrm{N} \\
& \beta \text { : 回転軸(短軸) と } \vec{V} \text { のなす角。 } \\
& \rho \text { : 空気密度 } \mathrm{kg} / \mathrm{m}^{3} \\
& \omega: \text { 回転速度 } \mathrm{rev} / \mathrm{s}
\end{aligned}
$$

\section{2. 風 洞 実 験}

短軸回りに回転するラグビーボールに働く空気力を 測定した。風洞実験の概観を図 1 ( a ) に示す。東海大 学工学部航空宇宙学科のゲッチンゲン形低速風洞を使 用した. 吹出しロのサイズは, $1.5 \mathrm{~m} \times 1.0 \mathrm{~m}$ である. 


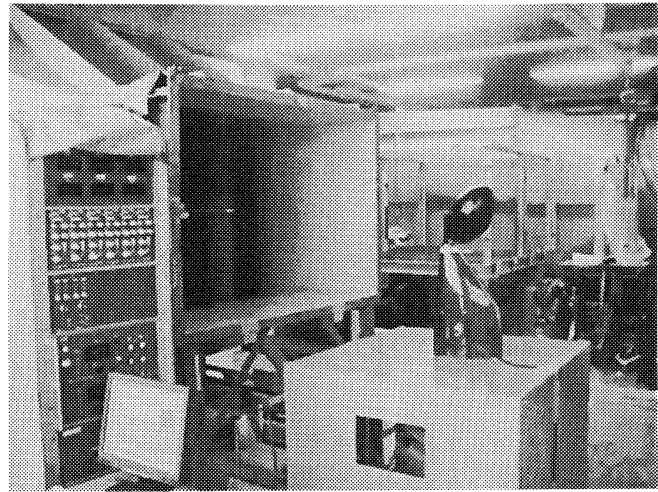

(a) View of the experimental set-up

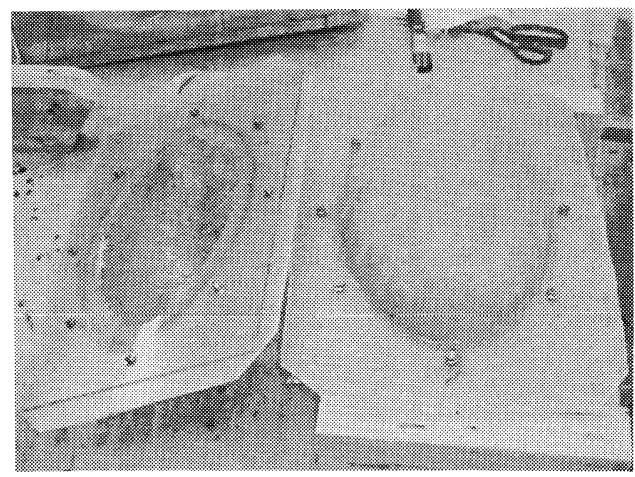

(b) Molding

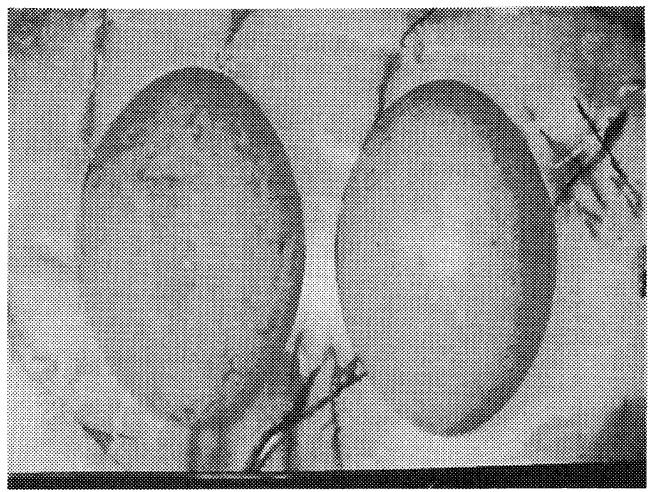

(c) Molded rugby ball

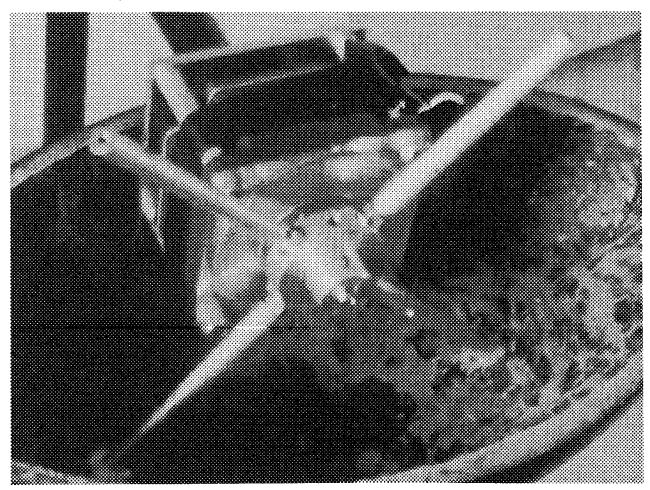

(d) Spinning mechanism

Fig. 1 Experimental set-up and rugby ball

この風洞にワールドカップ公式球であるギルバード社 の実物大模型を備え付け，実験した。実物大模型は， 以下の手順で制作した。

（1）実際のボールに固形離型剂(3 時間ごとに 5 回)と水性離型剤(12 時間ごとに 2 回)を塗布して半球 ずつ作業する。

（2）ボールにはけでゲルコート材を塗る。

（３）グラスマットを積層し，図 1（b ）の雌型を完 成.

（4）完成した雌型に（1）と同様の離型剂処理をす る.

（5）雌型にゲルコート材を塗り，さらに350 番の グラスマットを積層する。

（6）雌型から製品を取り出して完成.

完成した実物大模型は, 肉厚 $0.6 \sim 0.8 \mathrm{~mm}$ で, 片側 約 $155 \mathrm{~g}$ である。熱収縮を防ぐため, 一連の作業は恒 温室で行い, $1 \%$ 以内のひずみであった.ボールの縫 い目および表面のぼつぼつ感も再現された，回転むら を抑えるため, 縫い目のない側 [図 1(c)の右側] の
底の肉厚を若干厚くした。

ボールの短軸に沿って，図 1(d)のように内部にモ ータ(AXU 425 A-A, Oriental Motor)を組み込んだ. このモータをモータコントロールユニット (AXUD 90

A, Oriental Motor)で制御した。回転速度は90〜 $1000 \mathrm{rpm}$ 程度まで変化可能である.

空気力と各变数の定義を図 2 に示した。図 2 の左図 は上からの目線, 右図は吹出し口からの目線である. ボールは短軸回りに回転しているが, 図 2 では流入す る風の速度べクトル $\vec{V}$ と長軸が直交する瞬間, つま り投影面積が最大になる瞬間を描いた，当然，投影面 積は回転に伴い, 時々刻々変化する，回転する短軸と

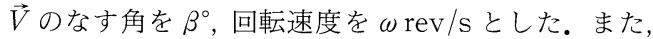
ラグビーボールに働く空気力はストラットタイプの 6 分力てんびん(LMC-6524-50 S, Nissho Electric Works)で 5 秒間測定した.サンプリング周波数は $1000 \mathrm{~Hz}$ にした。風速 $|\vec{V}|$ は $15,20 \mathrm{~m} / \mathrm{s}$ ， $\omega$ は 2 10 $\mathrm{rev} / \mathrm{s}, \beta$ は $90^{\circ}$ の範囲に設定し, 実験を行った。 実際のゴールキックの $|\vec{V}|$ は $26.4 \mathrm{~m} / \mathrm{s}$ 程度と報告さ 


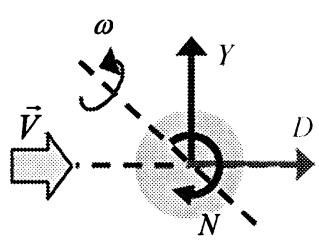

Top view.

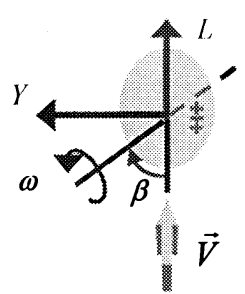

Front view.
Fig. 2 Definitions of aerodynamic forces and characteristic parameters

れている(5)が，モータのトルク不足により，| $|\vec{V}|>20$ $\mathrm{m} / \mathrm{s}$ の領域では, 特に低回転速度でボールを回転させ ることができなかった。ローリングモーメントとピッ チングモーメントはほぼ零であったため, 実質的には

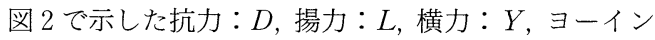
グモーメント： $N$ を測定した。

\section{3. 実 験 結 果}

回転するボールに働く抗力 $D$ と揚力 $L$ の時間変化 を $|\vec{V}|=15 \mathrm{~m} / \mathrm{s}, \omega=2 \mathrm{rev} / \mathrm{s}, \beta=90^{\circ}$ の場合について 図 3 に示した。縦軸は電圧, 横軸は時間である。縦軸 の電圧は，ボールおよび支柱等に働く空気力と等価で ある.この図 3 では, 両者に働く空気力の電圧を示し たが，図 4 以下では，支柱等に働く空気力を差引くこ とにより，ボールのみに働く空気力を示した。

抗力 $D$ と揚力 $L$ とも 1 秒間に約 4 周期, 5 秒間で は約 20 周期ある。これは, ラグビーボールに働く空 気力が半回転で 1 周期分の変化をするためである. 風 に対して, 投影面積が最大になる瞬間(ボール長軸と $\vec{V}$ が直交)にDは最大となり，投影面積が最小になる 瞬間(ボール長軸と $\vec{V}$ が平行)に $D$ は最小になる。抗 力 $D$ が最大もしくは最小になる瞬間に $L$ は変動の最 大と最小の間に位置する。両者の位相差は約 $90^{\circ}$ $(0.0625 \mathrm{~s})$ であった。また，Lの時間変化には，低周 波数成分が存在する。この原因はモータのトルク不足 と考える。低回転速度では，回転が安定するまでに時 間を要した。目視で回転が安定したことを確認した 後, デー夕収集したが, 微小振幅の低周波数成分は存 在した。

次に時間平均した空力係数を図 $4 \sim 7$ に示す. 抗力 係数 $C_{D}$ をスピンパラメータ $S p$ の関数として図 4 に, 揚力係数 $C_{L}$ を図 5 , 横力係数 $C_{Y}$ を図 $6, \exists$ ヨング モーメント係数 $C_{n}$ を図 7 に示した。それぞれの定義 は式(1)〜 (3)のと抢りである.

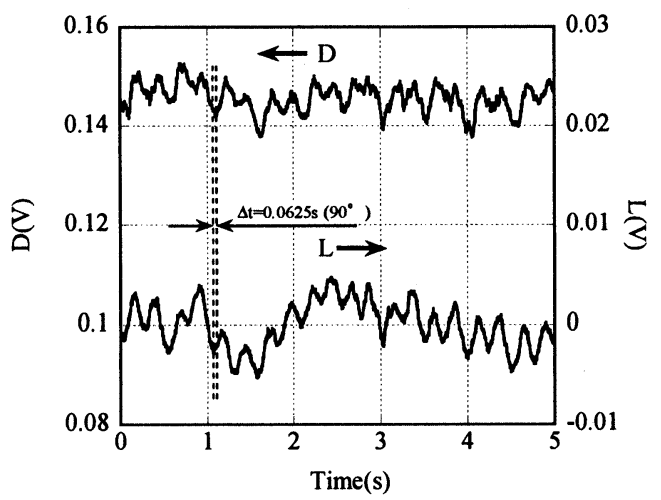

Fig. 3 Time variations of the drag and the lift at $\beta=90^{\circ}$ and $2 \mathrm{rev} / \mathrm{s}$

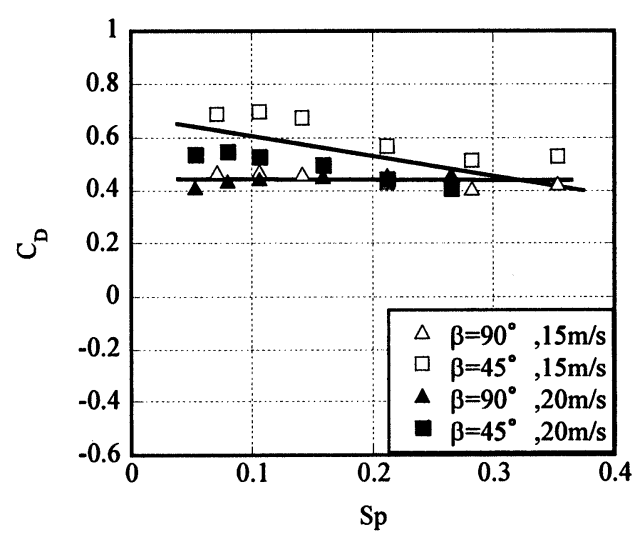

Fig. 4 The drag coefficient, $C_{D}$, as a function of the spin parameter, $S p$

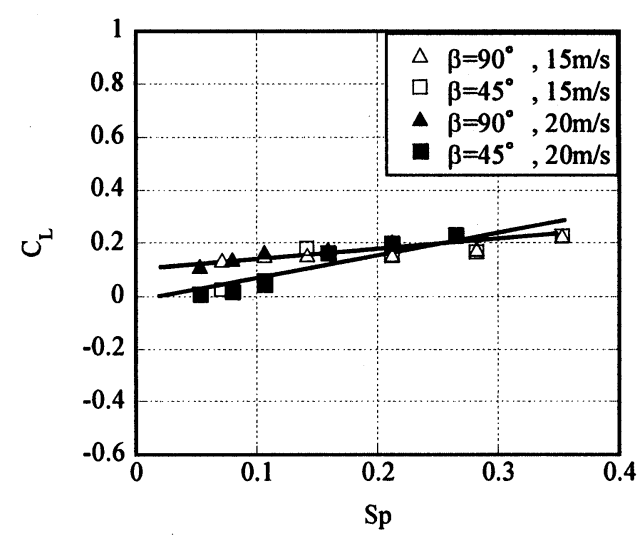

Fig. 5 The lift coefficient, $C_{L}$, as a function of the spin parameter, $S p$ 


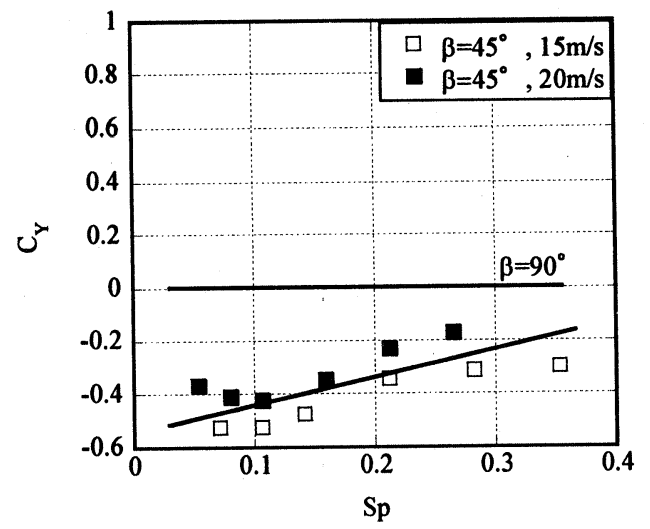

Fig. 6 The side force coefficient, $C_{Y}$, as a function of the spin parameter, $S p$

$$
\begin{aligned}
& C_{D, L \& Y}=\frac{D, L \& Y}{1 / 2 \rho|\vec{V}|^{2} V_{b}^{2 / 3}} \\
& C_{n}=\frac{N}{1 / 2 \rho|\vec{V}|^{2} V_{b}} \\
& S p=\frac{\pi \omega V_{b}^{1 / 3}}{|\vec{V}|}
\end{aligned}
$$

ここで, $\rho$ は空気密度， $V_{b}$ はボールの体積である．測 定值より， $V_{b}=4.8 \times 10^{-3} \mathrm{~m}^{3}$ とした。また， $S p は ，$ $|\vec{V}|=15 \mathrm{~m} / \mathrm{s}$ かつ $\omega=10 \mathrm{rev} / \mathrm{s}$ の場合 $S p=0.35,|\vec{V}|$ $=20 \mathrm{~m} / \mathrm{s}$ かつ $\omega=2 \mathrm{rev} / \mathrm{s}$ の場合 $S p=0.053$ である.

図 4 より, $\beta=90^{\circ}$ では, $C_{D}$ は $S p に も|\vec{V}|$ にもよ らず，一定值の 0.44 になる. $\beta=45^{\circ}$ では， $C_{D}$ は $S p$ とともに減少する. 実際のキックの条件である $S p>$ 0.05 以上では, $C_{D}$ は $S p$ に対して直線的に減少する.

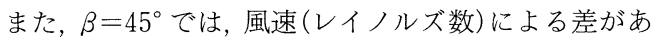
る。過去に行われた回転するゴルフボール(6)の実験 では, 空力係数のレイノルズ数依存性が無視できる程 度であったため, Spのみで整理されてきた。そこで 今回もレイノルズ数依存性は実験誤差の範囲と考え無 視し，Spのみでデータを整理した。短軸回りに回転 するラグビーボール空力係数のレイノルズ数依存性に ついては, 今後の課題である。また， $\beta$ による $C_{D}$ の 大小比較をすると, $\beta=45^{\circ}$ のほうが $\beta=90^{\circ}$ より大き い.この理由は, 風に対する投影面積にある。ボール は短軸回りに回転しているが, $\beta=45^{\circ}$ のほうが時間 平均した投影面積が大きいためである。図 5 より, $S p$ $>0.05$ 以上では, $C_{L}$ は $S p$ に対して直線的に増加す る. $|\vec{V}|$ 依存性はほとんどなく, $C_{L}$ の増加はマグヌ ス力のためである. $\beta$ による $C_{L}$ の大小比較をすると, $\beta=90^{\circ}$ のほうが $\beta=45^{\circ}$ より大きい. 差は $S p$ が小さ い領域ほど大きい. $\beta=90^{\circ}$ では, 回転軸と $\vec{V}$ が直交

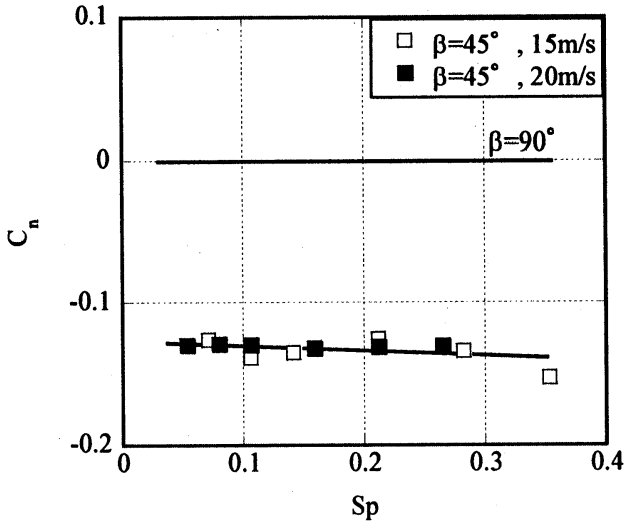

Fig. 7 The yawing moment coefficient, $C_{n}$, as a function of the spin parameter, $S p$

するため, 最大のマグヌス力となるが, $\beta=45^{\circ}$ では, 回転するボールと $\vec{V} と の$ 相対速度が減少するため, マグヌスカが小さくなる.図 6 と図 7 には $C_{Y}$ と $C_{n}$

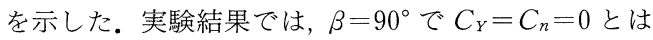
ならなかった。この原因は, 支柱が風にさらされてい るためと考える、滑面球の実験では，直径 $220 \mathrm{~mm}$ の 滑面球に対して $2 \mathrm{~mm}$ のピアノ線(直径比 $0.9 \%$ )で支 持した場合でも横力とヨーイングモーメントは零にな らなかった ${ }^{(7)}$. しかし, $\beta=90^{\circ}$ では, 上流側からの視 点で, ボールは幾何学的に左右対称となるため, $C_{Y}$ と $C_{n}$ は零と仮定し, $\beta=90^{\circ}$ の $\left|C_{Y}\right|$ と $\left|C_{n}\right|$ 分を各 $\beta$ のデータより, 差引いた。図 6 より, $\beta=45^{\circ}$ では, $C_{Y}$ は負である. 風に対して, 投影面積が最大(ボール長 軸と $\vec{V}$ が直交) となる瞬間には， $\beta$ によらず横力は働 かない.しかし，それ以外の瞬間には，ボールの上流 側に風が当たり，負の方向に横力が働く．その結果， 時間平均した $C_{Y}$ は $\beta=90^{\circ}$ 以外で負になる. $S p>$ 0.05 以上では, $C_{L}$ は $S p$ に対して直線的に増加する. 図 7 より, $\beta=45^{\circ}$ では, $C_{n}$ も負である. 理由は, $C_{Y}$ と同様である. $S p>0.05$ 以上では, $|\vec{V}|$ に依存せず, $C_{n}$ は $S p$ に対して直線的に減少する.

以上, 四つの空力係数を多項式で回帰する. 回帰式 は，飛しょう軌跡を計算する際に使用する．Spに関 してはすべての空力係数を一次で, $\beta$ に関しては, $C_{D}$ と $C_{L}$ は一次, $C_{Y}$ は三次, $C_{n}$ は二次で回帰した。 $\beta$ の単位は度 $\left(^{\circ}\right)$ である. 各回帰式と実験デー夕間の差 は, $C_{D}$ で $S D<0.054, C_{L}$ で $S D<0.048, C_{Y}$ で $S D$ $<0.056, C_{n}$ で $S D<0.026$ であった。

$$
\begin{gathered}
C_{D}(S p, \beta)=8.59 \times 10^{-1}-2.09 \times 10^{-1} S p \\
-\left(4.09 \times 10^{-3}+2.57 \times 10^{-3} S p\right) \beta \quad \cdots \cdots
\end{gathered}
$$




$$
\begin{aligned}
& C_{L}(S p, \beta)=\left(1.48 \times 10^{-3}+6.64 \times 10^{-3} S p\right) \beta \\
& \cdots \cdots \cdots \cdots(5) \\
& C_{Y}(S p, \beta)=\left(-1.74 \times 10^{-2}-3.21 \times 10^{-2} S p\right) \beta \\
& \quad+\left(8.62 \times 10^{-5}+1.71 \times 10^{-3} S p\right) \beta^{2} \\
& \quad+\left(1.20 \times 10^{-6}-1.51 \times 10^{-5} S p\right) \beta^{3} \cdots \cdots \cdots(6) \\
& C_{n}(S p, \beta)=\left(-4.89 \times 10^{-3}-4.32 \times 10^{-3} S p\right) \beta \\
& \quad+\left(5.44 \times 10^{-5}+4.80 \times 10^{-5} S p\right) \beta^{2} \cdots \cdots \cdots(7)
\end{aligned}
$$

\section{4. ま と め}

ラグビーのゴールキックを模擬するため, 短軸回り に回転するラグビーボールの風洞実験を行った。その 結果をもとに, 抗力係数, 揚力係数, 横力係数, ヨーイ ングモーメント係数をスピンパラメータと回転短軸と 風流入方向のなす角の関数として, 多項式で表した。 本研究は, 稲盛財団, 石本記念デサントスポーツ科 学振興財団, 科研費・若手 A (18680045)の助成を受け て行った. 感謝申し上げる.

\section{文献}

(1) Seo, K. et al., Flight Dynamics of the Screw Kick in
Rugby, Sports Engineering, Vol. 9, No. 1 (2006), pp. 4958.

(2) Seo, K. et al., Multi-Optimization of the Screw Kick in Rugby by Using a Genetic Algorithm, Sports Engineering, Vol. 9, No. 2 (2006), pp. 87-96.

(3) Seo, K. et al., Regular and Irregular Motion of a Rugby Football During Flight, The Engineering of Sport 5, Vol. 1 (2004), pp. 567-573.

(4) Takahashi, N. and Kobayashi, O., Auto-Rotation on Short Axis of Rugby Ball, Mechanical Engineering Congress, 2006 Japan, No. 06-1 (2006), pp. 123-124.

(5) Holmes, C. et al., Ball Launch Characteristics for Elite Rugby Union Players, The Engineering of Sport 6, Vol. 1 (2006), pp. 211-216.

(6) Naruo, T. and Mizota, T., Aerodynamic force measurement of a golf ball and $3 \mathrm{D}$ trajectory analysis, Nagare, Vol. 23 (2004), pp. 203-211.

( 7 ) Seo, K. et al., The Influence of a Supporting System on Aerodynamic Loads of a Soccer Ball in Wind Tunnel Test, Proceedings of Symposium on Sports Engineer. ing, (2006), pp. 73-78. 